\title{
A New Way of Providing Access: RDA and its Impact
}

by Deirdre Kiorgaard, Australian Committee on

Cataloguing Representative to the Joint Steering Committee for the Development of RDA

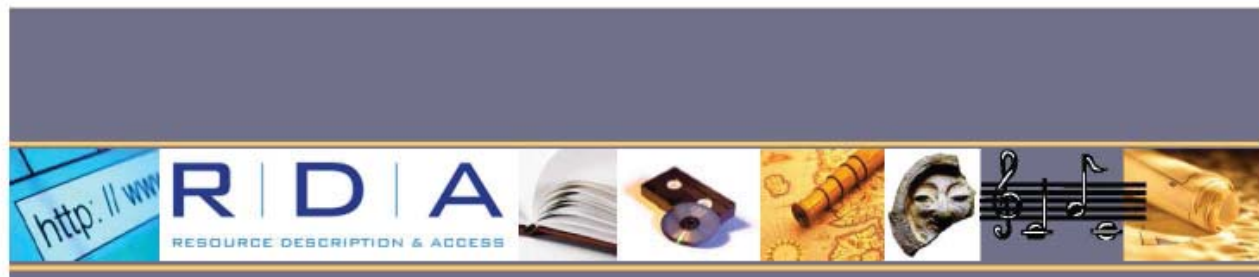

\section{A new way of providing access RDA and its impact}

Deirdre Kiorgaard

Australian Committee on Cataloguing Representative

to the Joint Steering Committee for the Development of RDA 


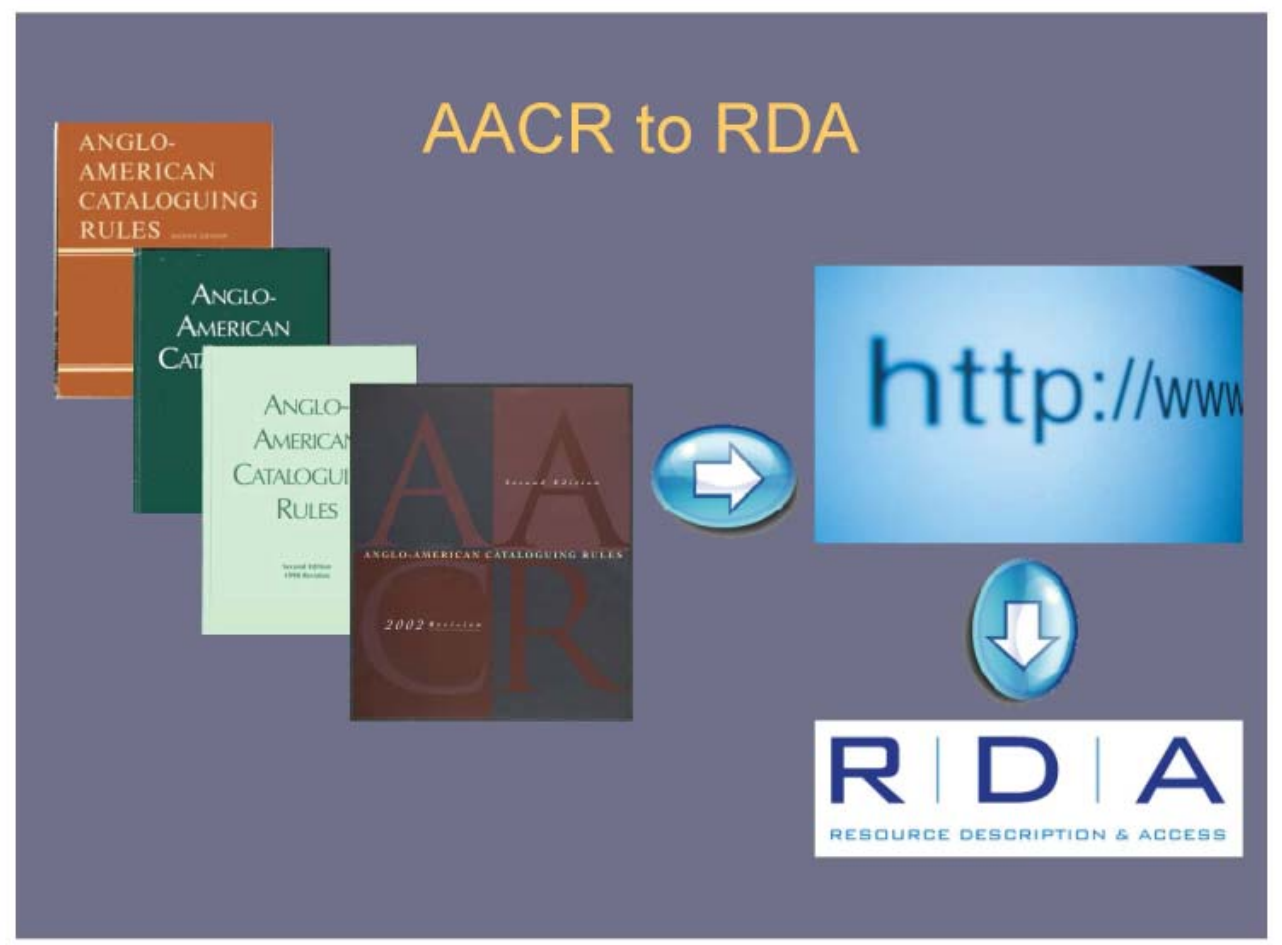

\section{AACR and descriptive cataloguing}

$>$ AACR is a robust standard, but ...

- 'Class of materials' approach is no longer valid

- Need for principles-based instructions

- Need for extensibility

- Designed for the card catalogue not digital world

- Data needs to be usable in the web environment

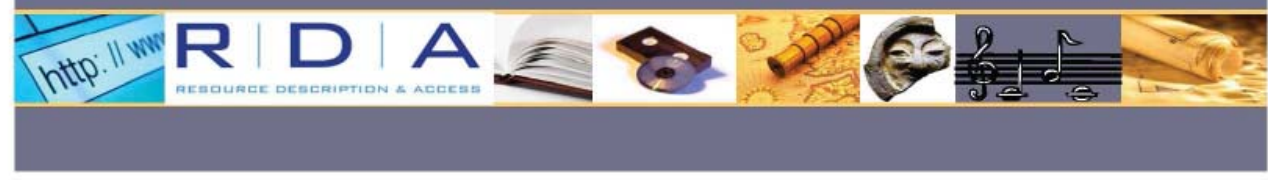




\section{Brave new world?}

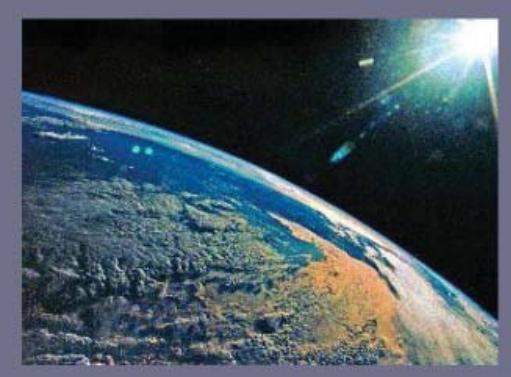

$>$ The power of the search engine

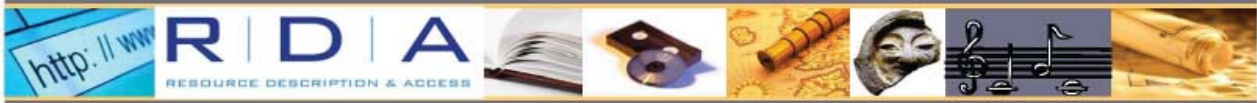

\section{Next generation catalogues}

- tagging

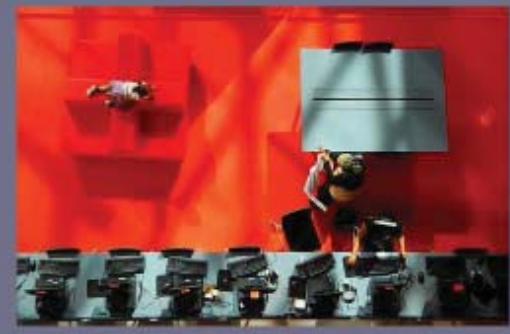

- links

- reviews

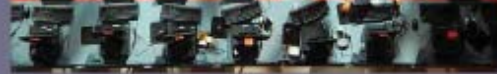

- full text

synonym control

- table of contents 


\section{The (not so) secret life of catalogue data (1)}

"metadata increasingly appears farther and farther away from its original context" Shreeves, Riley and Milewicz (2006).

$>$ Shared library databases

$>$ Digitisation projects

$>$ Institutional repositories
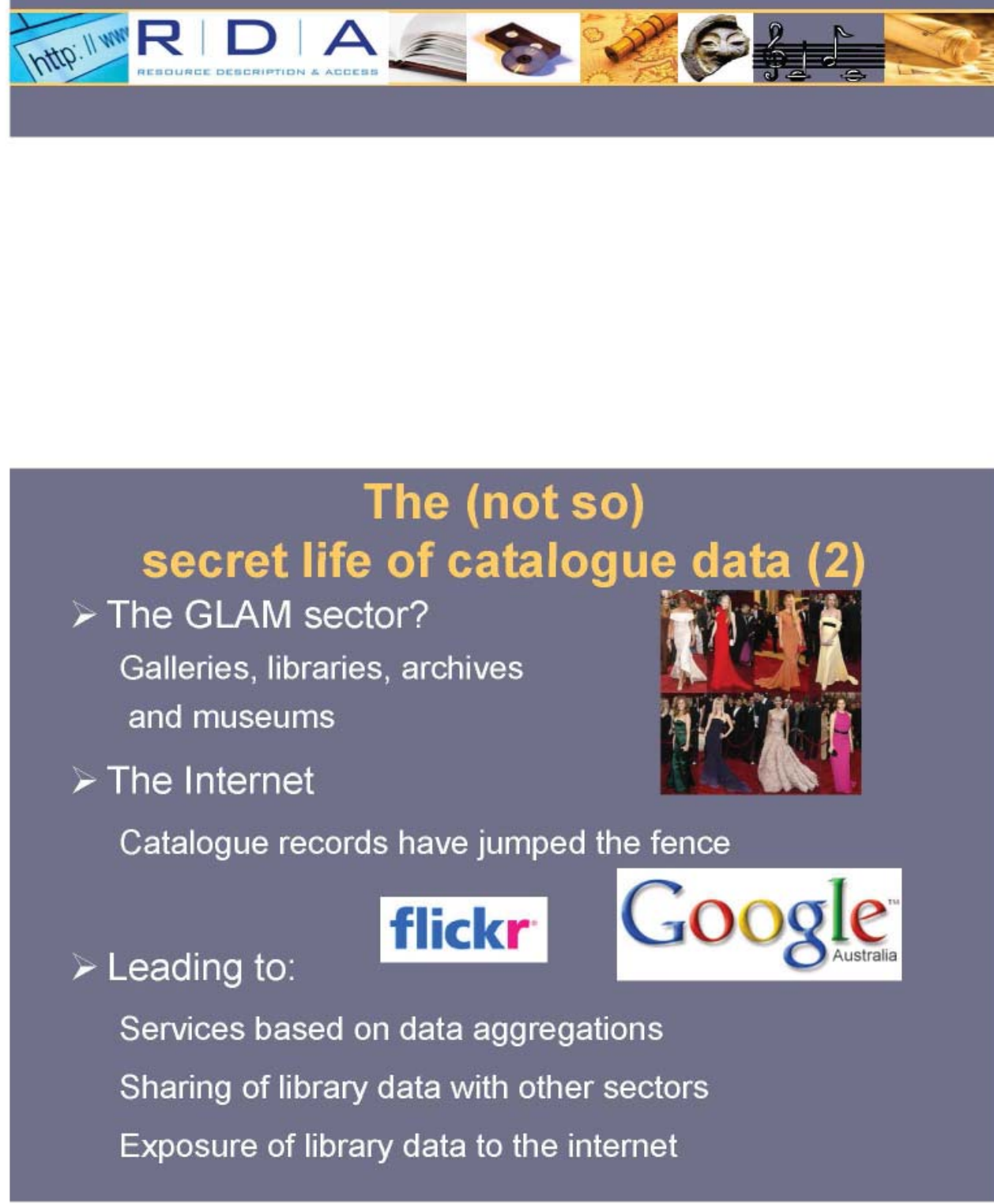


\section{RDA in the digital world}

$>$ Clearly defined element set

- better granularity, improved mapping to other schema, e.g. Dublin Core, ISBD, MODS/MADS, MARC21

$>$ Greater emphasis on relationships

- Better navigation and displays

$>$ Better interoperability - common vocabularies

- Content type, carrier type, media type; Relationship designators; Encoding formats, etc.

- Making vocabularies accessible

$>$ RDA and the semantic web

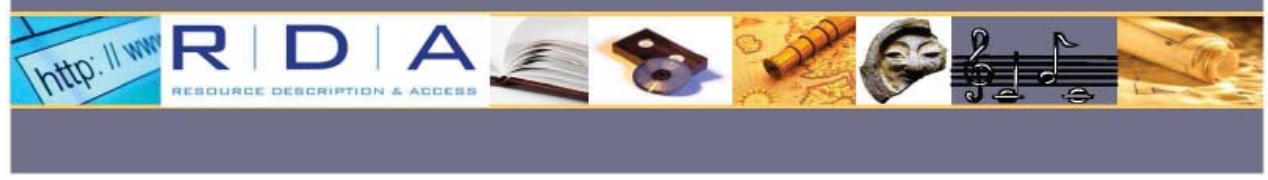

\section{RDA and FRBR/FRAD/FRSAR}

- IFLA models

Functional Requirements for Bibliographic Records

Functional Requirements for Authority Data

Functional Requirements for Subject Authority $\underline{\text { Records }}$

- Identify \& define bibliographic entities, attributes and relationships

- Map data elements to the specific user tasks they assist.

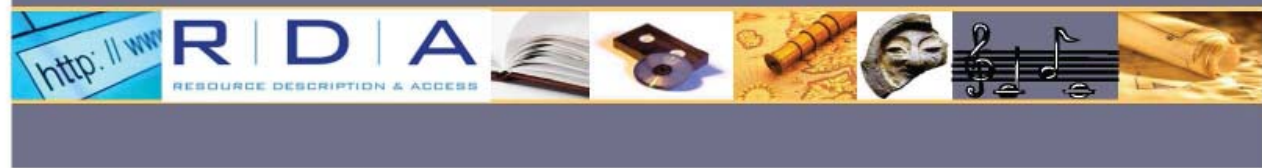




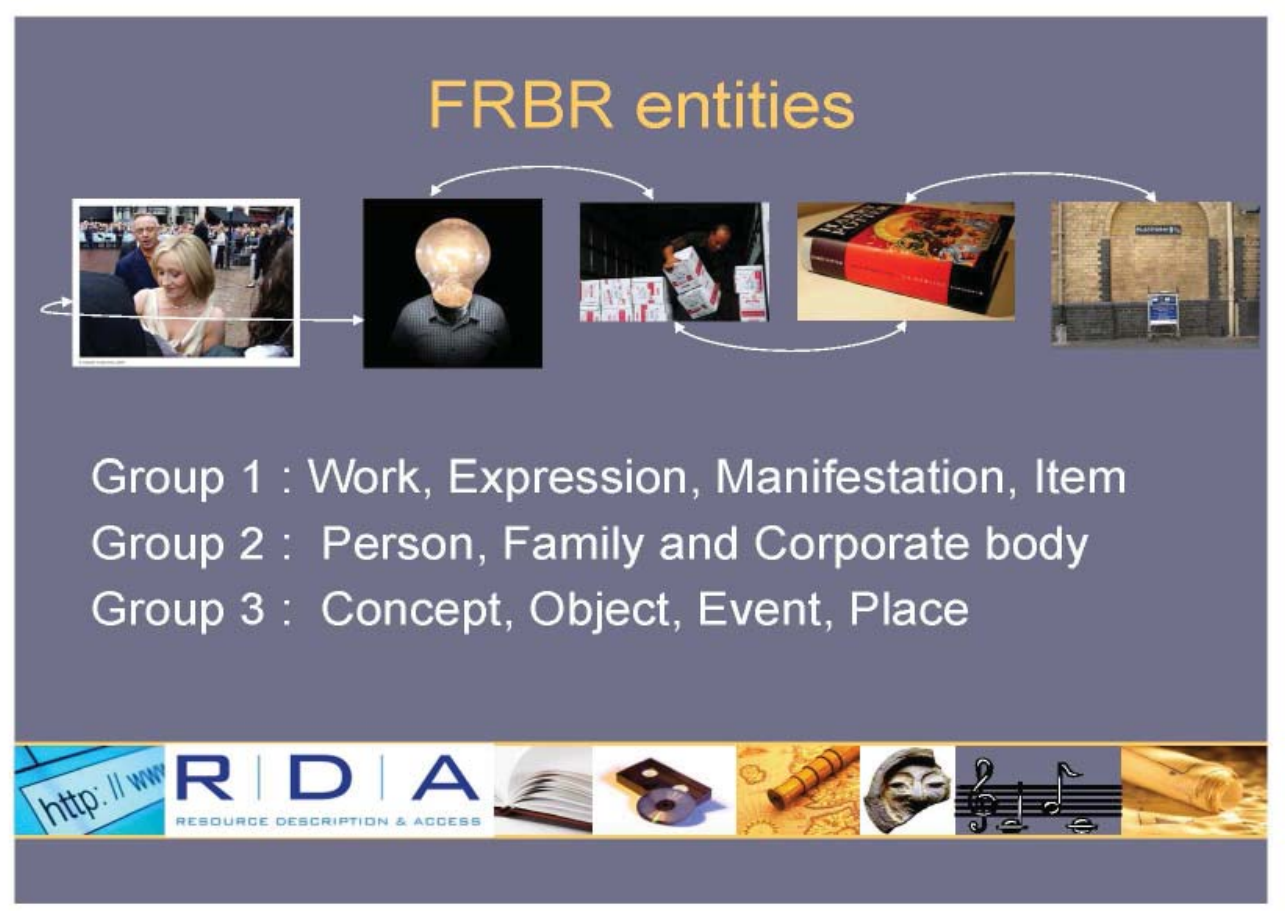

\section{FRBR in practice}

$>$ Used in databases

Red Light Green, Fiction Finder, xISBN,

Austlit, Music Australia

$>$ Used in library systems and catalogues VTLS - Virtua

$>$ FRBR Bibliography

$>$ http://www.ifla.org/NI//s13/wgfrbr/bibliography.htm 


\section{FRBR in practice - Fiction finder (1)}

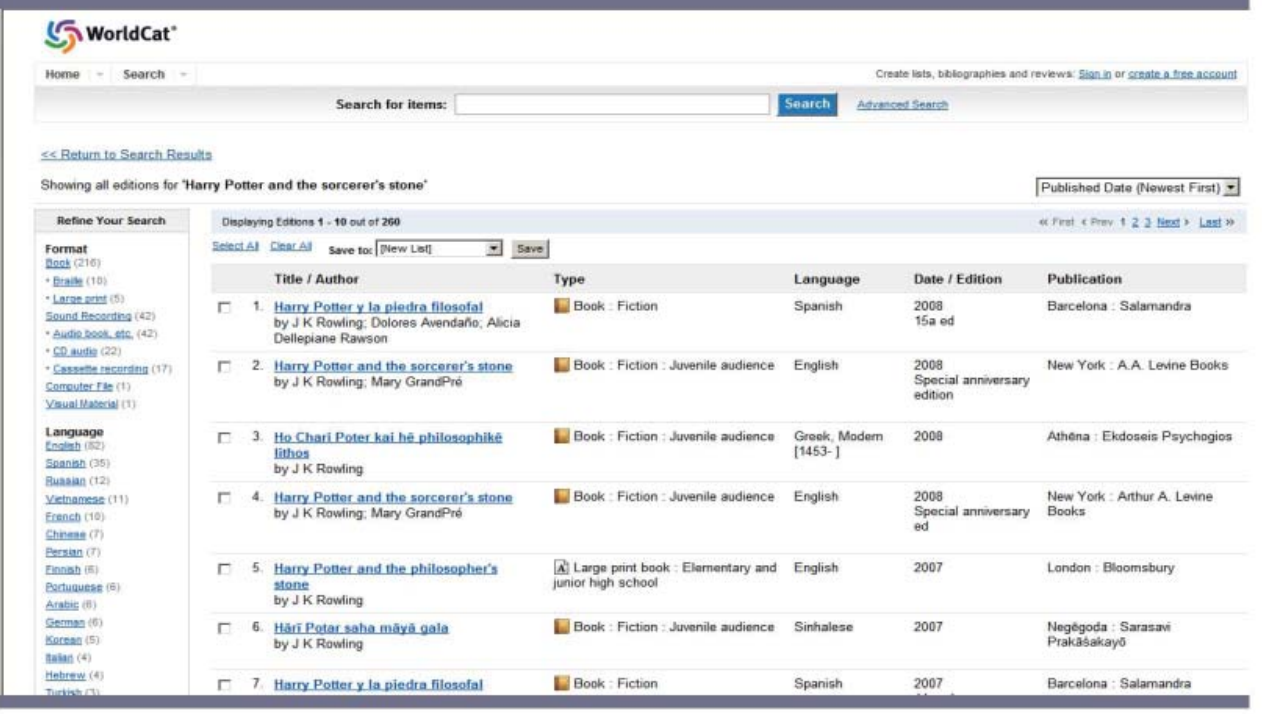

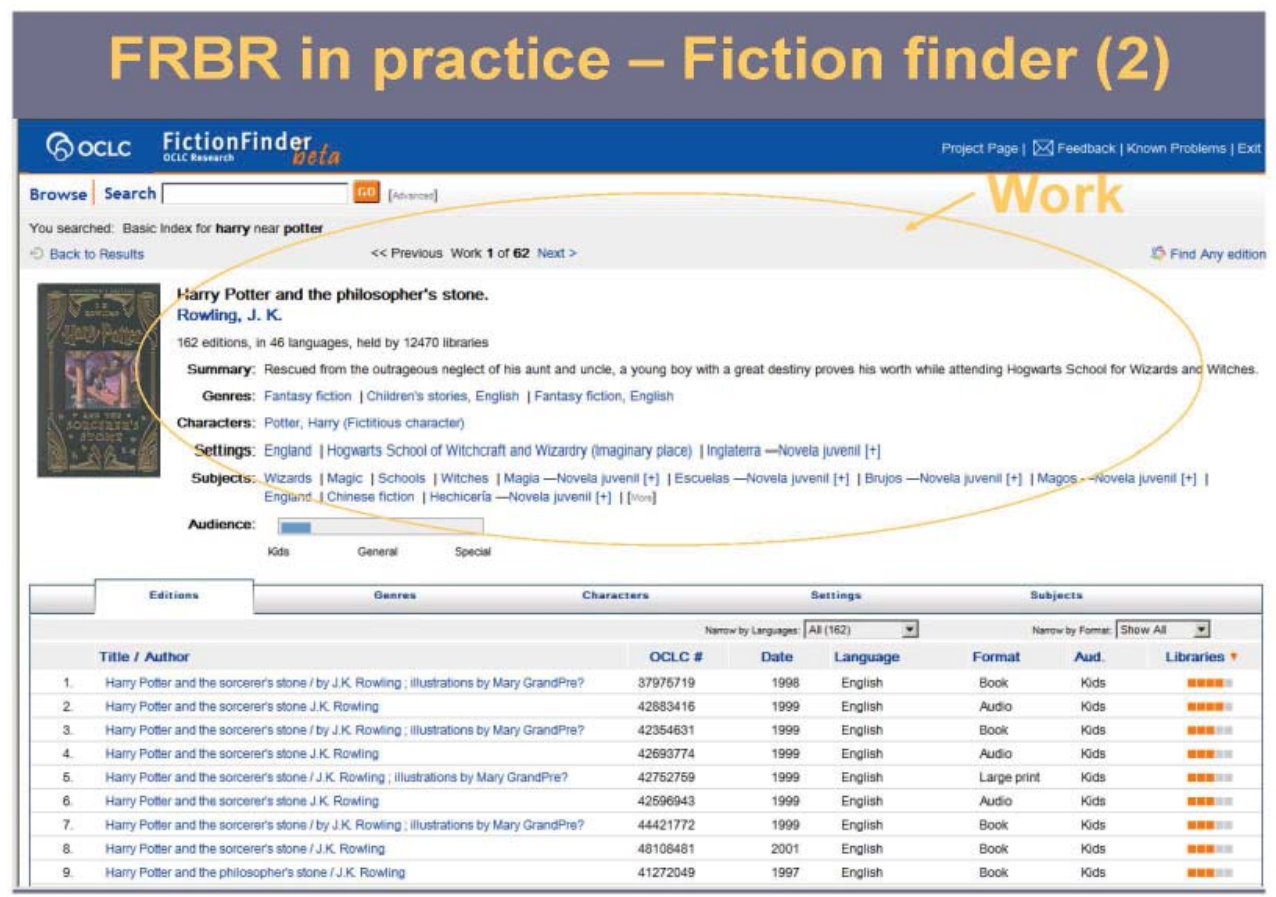




\section{FRBR in practice - VTLS}

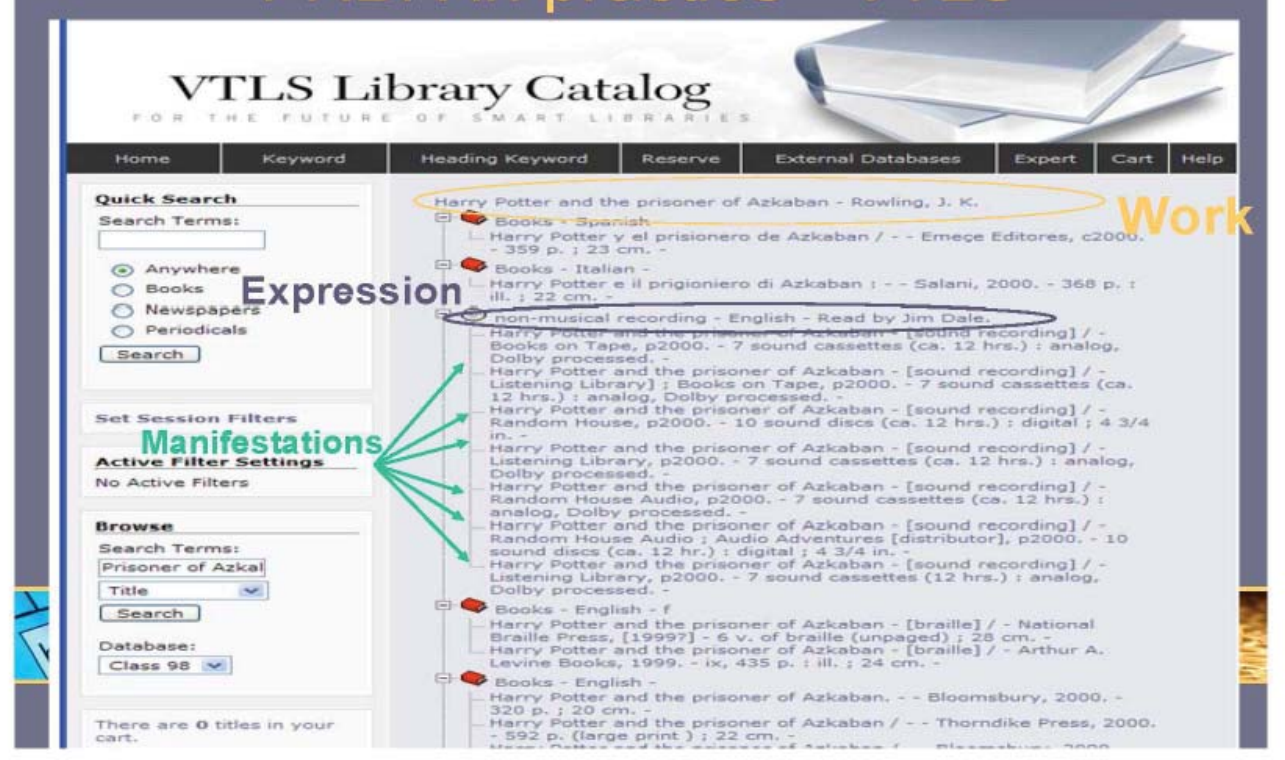

\section{FRBR in practice - Austlit (1)}

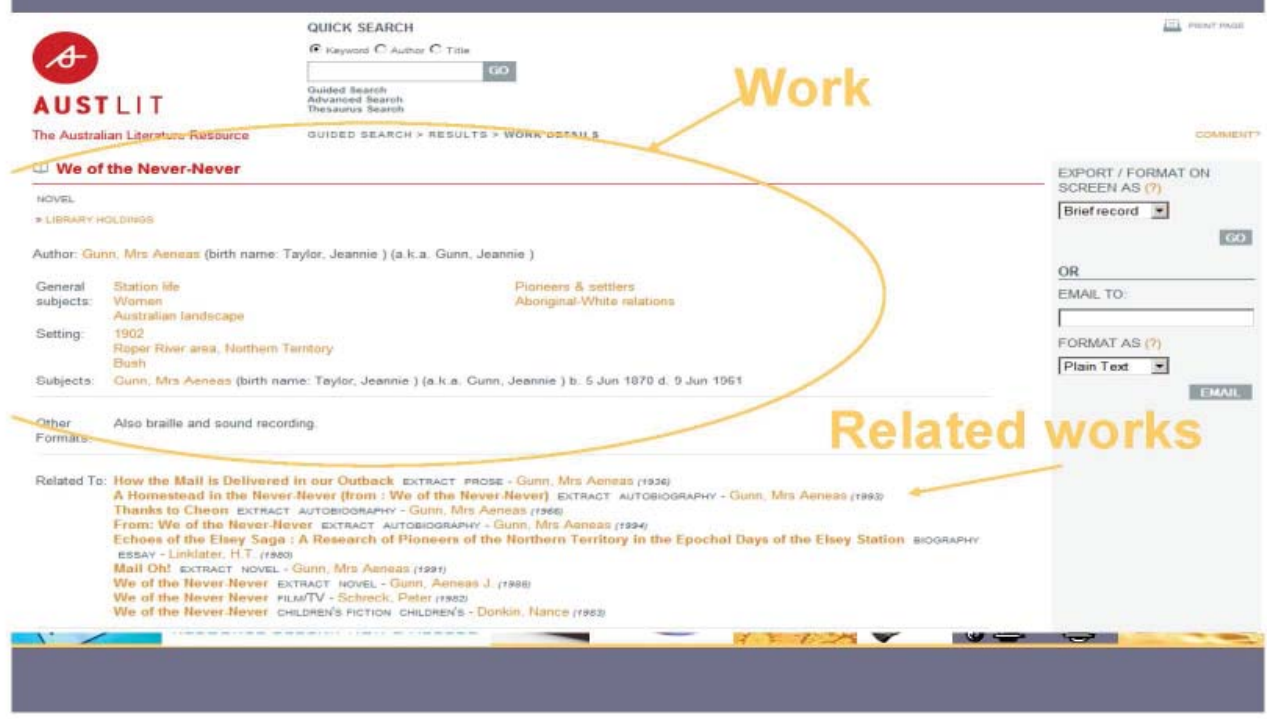




\section{FRBR in practice Austlit (2)}

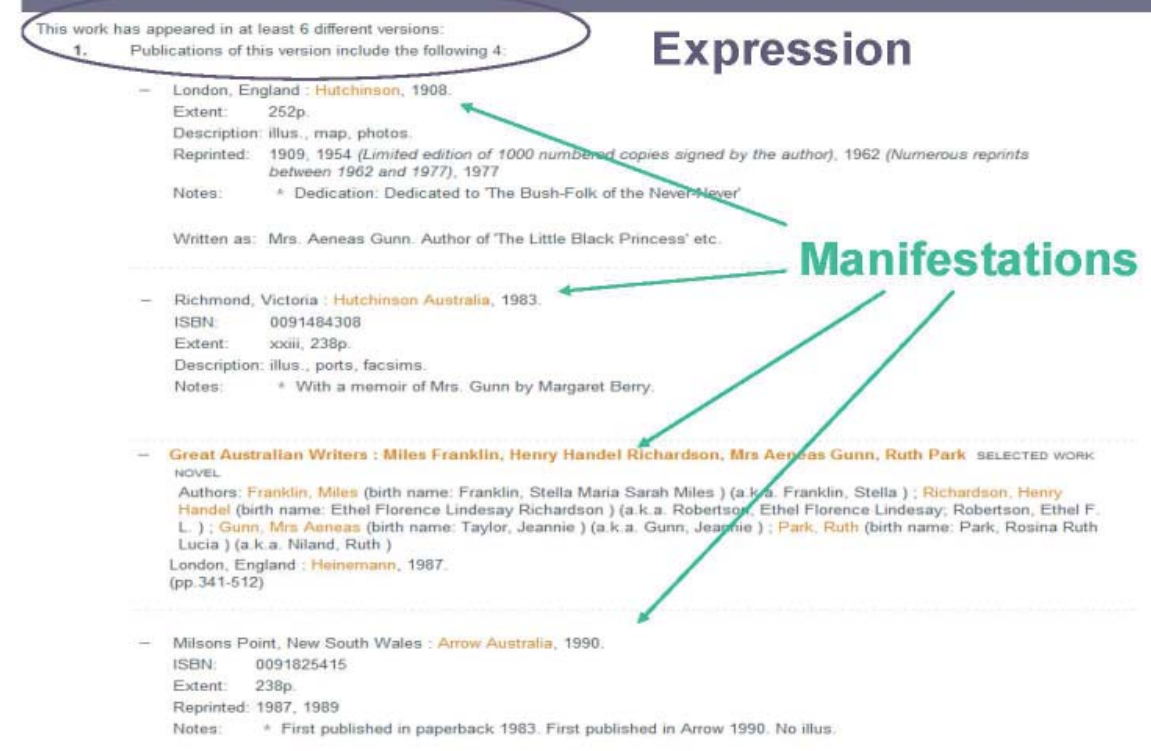

\section{Benefits of FRBR}

$>$ A new way of providing access

- Improved navigation of the catalogue for users

- Improved catalogue displays

- For researchers - a more organised display

- For the general public - a less cluttered display

$>$ Improved efficiency of data creation \& maintenance

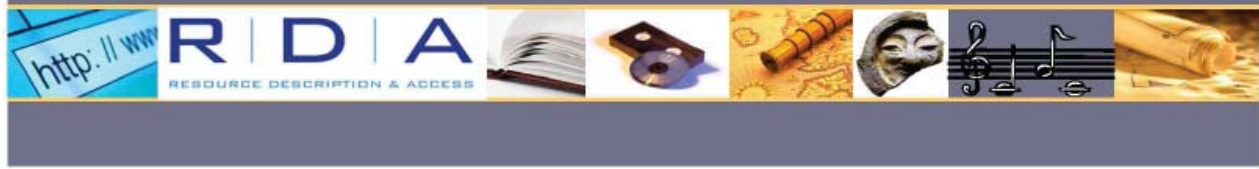




\section{RDA implementation scenarios}

RDA needs to support:

$>$ The present - data stored in bibliographic records, authority records, and holdings records - Linked records or flat file

$>$ The future - relational or object-oriented databases

- Separate records for each entity

- Links using persistent identifiers

http://www.collectionscanada.gc.ca/jsc/docs/5editor2.pdf

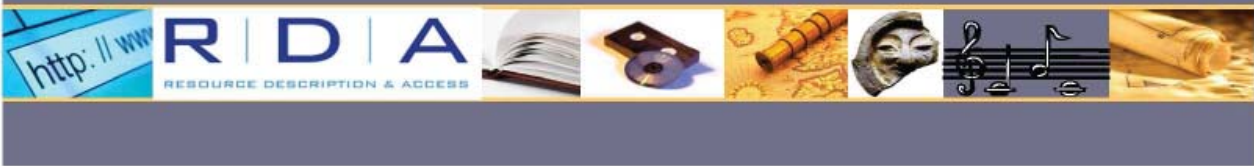

\section{Advantages of RDA for cataloguers}

$>$ Better coverage

- Visual resources, archival resources

- Online resources

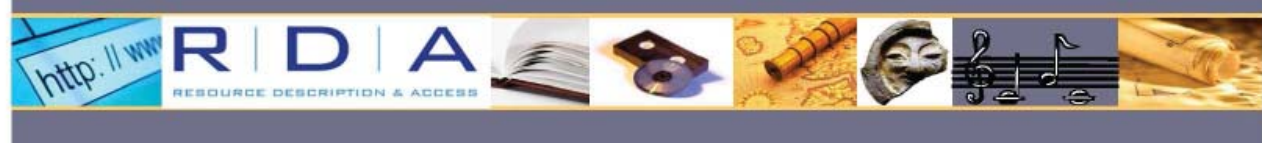




\section{Sacred Scriptures}

RDA changes from AACR2 25.18A Preferred titles for parts of the Bible:

$>$ The Old Testament and New Testament spelt out - not abbreviated to "O.T." and "N.T."

$>$ "and others" used in place of "et al." in preferred access points for version of the Bible identified by the name of the translator

$>$ Preferred titles for individual books of the Bible position the name of the book immediately following "Bible" rather than interposing the name of a Testament.

$>$ Preferred titles in the form "Bible. Old Testament", "Bible. New Testament", and "Bible. Apocrypha" are used to identify those groupings of the Bible as aggregate works.

(See the 5JSC/LC/8 series for background information.)

\section{Liturgical works, theological creeds,} confessions of faith, etc.

$>$ AACR2 25.19B requirement that the theological creed, confession of faith, etc., be accepted by one or more denominational bodies has been removed.

$>$ AACR2 25.22B use of the abbreviation "Ms" for "Manuscript" has been removed. 


\section{Sample - RDA instructions}

$>$ RDA as a cataloguing tool

Interactive and online Integration with policies and processes

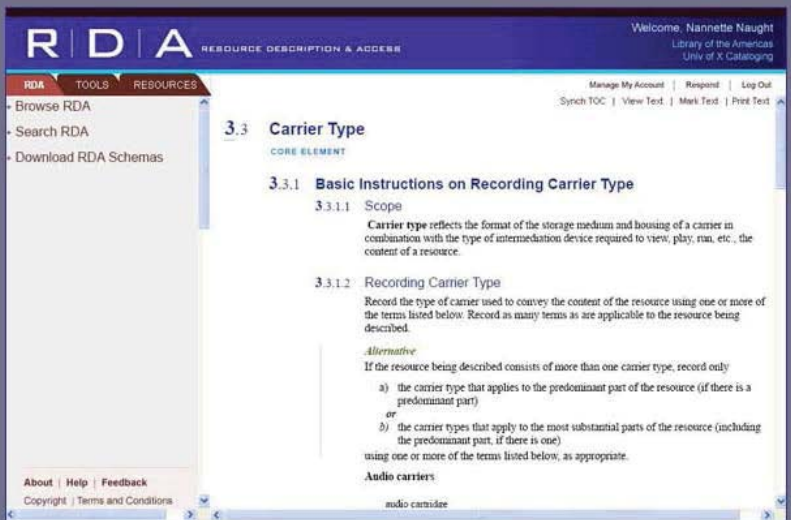

\section{Sample - RDA vocabulary}

\begin{tabular}{|c|c|c|}
\hline R & 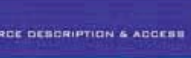 & 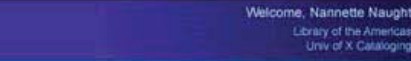 \\
\hline RDA TOOLS RESOURCES & \multirow{2}{*}{\multicolumn{2}{|c|}{ Leson }} \\
\hline $\begin{array}{l}\text {-Browse } \\
\text {; schema Dictonary }\end{array}$ & & \\
\hline $\begin{array}{l}\text { - ERO } \\
\text { - Group } 1 \text { Entses }\end{array}$ & \multicolumn{2}{|c|}{ RDA Element: Carrier Type } \\
\hline 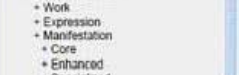 & \multicolumn{2}{|c|}{ 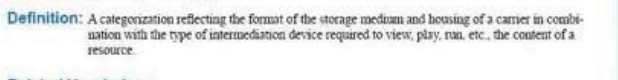 } \\
\hline & \multicolumn{2}{|l|}{ Related Vocabulary } \\
\hline 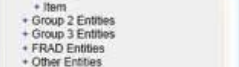 & 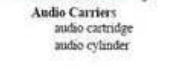 & \multirow{3}{*}{ 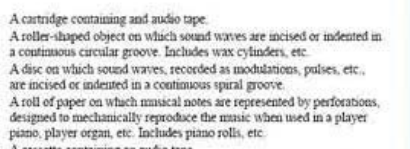 } \\
\hline 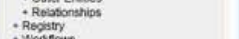 & andito disc & \\
\hline 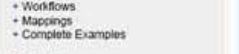 & matio roll & \\
\hline - Search & mudocassette & \multirow{2}{*}{ 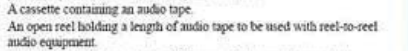 } \\
\hline - C & & \\
\hline - Downiload & sendid tarck reel & \\
\hline About / Help / Feestoack & Computer Carriens & \multirow{4}{*}{ 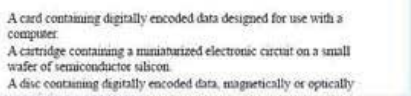 } \\
\hline copyingen i Terms ano constions & & \\
\hline & computer chap cartidige & \\
\hline & compiniter disc & \\
\hline
\end{tabular}




\section{Preparing for RDA - 1}

\section{$>$ Learning about FRBR and RDA}

http://wnw.collectionscanada.gc.ca/isc/rda.html

$>$ Keeping up to date

$>$ Implementation strategy

http://www.nla.gov.au/lis/stndrds/grps/acoc/index.html

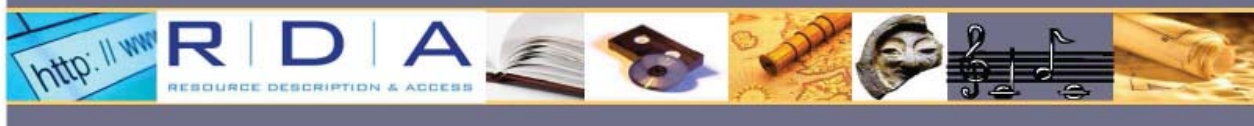

\section{Preparing for RDA - 2}

\section{$>$ MARC}

- 2009-06/3: New coded values for RDA media carriers in the MARC 21 Bibliographic Format.

- 2009-06/1: Accommodating Relationship Designators for RDA Appendix $\mathrm{J}$ and $\mathrm{K}$ in MARC 21 Bibliographic and Authority Formats

- 2009-01/3: Identifying work, expression and manifestation records in the MARC 21 Bibliographic and Authority Formats

- 2009-01/2: New content designation for RDA elements: Content Type, Media Type, Carrier Type in the MARC 21 Formats

$>$ System changes

$>$ Training

$>$ Purchasing RDA
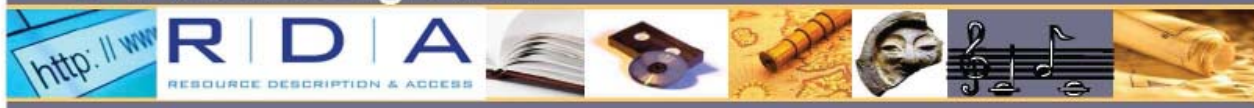


\section{Conclusion - thank you}

\section{$>$ list of images on final slide - presentation}

will be available on NLA website

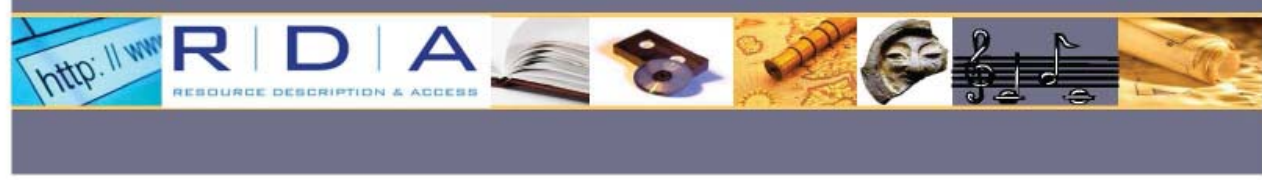

Images from Flickr (used under Creative Commons licenses)

- "Seattle Public Library" by Jeff Maurone http://wnw. flickr.com/photos/ieffmaurone/2505572445/

- "Harry Potter Books being brought into Barnes and Nobel today" by Snappy.joneS hittp:/ www: flickr.com/photos/swift/839373017/

> "Order of the Phoenix Premiere@ Leicester Square 07.03.2007" by Melanie Mcdermott. hittp://wnw. filickr.com/photos/pierrotsomepeople/710443488/

> "Harry Potter's platform!" by tripu hitto://wnw.flickr.com/photos/tripu/267155109/

> "Just full of ideas" by Cayusa http://www. flickr.com/photos/cavusa/981372736

\section{Images from the Internet}

- Image of Earth from space on website by Liz Strauss

http://www. successful-blog.com/2007/09/

- Image of stars on red carpet on website by PopSugar hitto://popsugar.com/150953 